\title{
Comparing Mortgages with Different Payment Frequencies
}

\author{
Arefaine G. Yohannes
}

\begin{abstract}
The biweekly-payment mortgage is an alternative to the monthly-payment mortgage. In this study, logistic regression is used to determine the influence of demographic characteristics on the choice between these two types of mortgages. Of the six independent variables that were considered, only two had significant influence on mortgage choice. They were the frequency of paydays and education.
\end{abstract}

In the last few years, there have been a number of studies dealing with mortgage choice. Many of these studies dealt with the choice between fixed-rate mortgages and adjustable-rate mortgages. Examples of such studies include Brueckner and Follain (1988), Chmura (1989), Dhillon, Shilling and Sirmans (1987), Gardner, Kang and Mills (1987), and Tucker (1989).

Other studies examined the choice between fifteen-year and thirty-year fixedrate mortgages. Examples of such studies include Dhillon, Shilling and Sirmans (1990) and Yohannes (1986).

In this study, mortgages with different payment frequencies are compared. Specifically, this study deals with the choice between the biweekly-payment mortgage and the monthly-payment mortgage.

Although the biweekly-payment mortgage (BPM) has been around for some time in other countries such as Canada, it is fairly new in the United States. For this reason, it is not as widely known or as widely used as the monthly payment mortgage (MPM).

Also, research on the BPM is limited. Yohannes (1988) evaluated fast-pay mortgages, including BPMs, from the borrower's point of view. Shilling and Sirmans (1987) examined the pricing of fast-pay mortgages from the lender's point of view.

In a BPM, half of the monthly payment of a MPM is paid every two weeks. That means 26 payments are made in a year. In undiscounted terms, the 26 biweekly

Arefaine G. Yohannes - School of Management, The University of Michigan-Dearborn, 4901 Evergreen Road, Dearborn, MI 48128. 
payments are equal to 13 monthly payments. The extra monthly payment and the frequency of payments associated with the BPM reduce the term of a 30-year mortgage by about one-third. In addition, the home owner pays down the principal faster than she or he would with a MPM.

On the negative side, the BPM involves larger annual payments than a MPM. Furthermore, for tax purposes, the annual interest deductions associated with the BPM are smaller than those of the MPM. Finally, unless the biweekly payments are made electronically, the frequency of payments would be burdensome for borrowers and lenders.

The purpose of this study is to examine the influence of specific borrower characteristics on the choice between the BPM and the MPM. The borrower characteristics that were included in this study are frequency of paydays, income, net worth, education, age and marital status. The hypotheses pertaining to these factors are given in the next section.

With the exception of frequency of paydays, the borrower characteristics listed in the previous paragraph were used in previous studies of mortgage choice. The studies cited above did not use the same variables. Apparently, the choice of variables depended on the type of mortgage choice under study and/or the availability of data. The authors do not claim that the list of variables included in this study is exhaustive or complete. However, at the time the survey form was prepared, we believed that the variables listed above would influence the mortgage payment frequency decision. To the extent that other important variables were left out, we hope that some of their effects would be captured by some of the variables that were included in the study. For example, the borrower's expected duration of stay in the house was not included in the model and it may be argued that this variable is an important factor. To the extent that younger home owners are more mobile than other home owners, age may be considered a proxy for mobility or the expected housing tenure.

\section{THE MOdEL}

Since the dependent variable is a categorical variable, the logistic regression model was used to determine the effects of borrower characteristics on the odds or probability of selecting a BPM.

The present value framework as well as probit and the logistic regression models were used in studies of mortgage choice. Chmura (1989) and Yohannes $(1986,1988)$ used the present value framework; Dhillon et al. $(1986,1989)$ used probit analysis and Gardner et al. (1987) and Tucker (1989) used logit analysis.

The probit and the logistic regression models are both appropriate for models in which the dependent variable is categorical or dichotomous. However, the logistic model was chosen for this study for the same reasons that are given in Tucker (1989). First, it does not require normality of the sampling distribution. Second, since the mid-range of the logit curve tends to be steeper than that of the probit curve, 
it is more likely to capture the effects of small differences between the characteristics of those who select the biweekly-payment mortgage and the characteristics of those who select the monthly-payment mortgage.

The logistic regression model is given by equation (1).

$$
E(Y)=\frac{\exp (W)}{1+\exp (W)}=[1+\exp (-W)]^{-1}
$$

where

$$
\begin{aligned}
W & =b_{0}+b_{1} X_{1}+\ldots+b_{p-1} X_{p-1} \\
& =\text { logit response function } \\
E(Y) & =\text { expected value of the dependent variable } \\
X ' \mathrm{~s} & =\text { independent variables } \\
b \text { 's } & =\text { model parameters } \\
\exp & =\text { base of the natural logarithmic system }
\end{aligned}
$$

Since equation (1) is non-linear, it is transformed into a linear function that can be used to estimate the parameters of the model. Specifically, if we let $E(Y)=P$, where $P$ is the probability that $Y$ will be one, equation (1) may be transformed into the logit response function:

$$
\ln (P / 1-P)=W=b_{0}+b_{1} x_{1}+\ldots b_{p-1} x_{p-1}
$$

The dependent variable, $Y$, was mortgage choice. It was coded a " 1 " if the BPM was selected; it was coded a " 0 " if a MPM was selected. As pointed out above, the independent variables were frequency of paydays, income, net worth, education, age and marital status.

One of the hypotheses that was tested is that borrowers who are paid biweekly will tend to choose the biweekly-payment mortgage. First, there is the convenience factor and secondly, if the people who are paid biweekly select a monthly-payment mortgage, there is a risk that those people will spend the money on something else before the mortgage due date arrives.

People with higher incomes and larger net worth would be expected to choose the BPM. They would be in a better position to handle the larger annual payments associated with the BPM. On the other hand, high-income borrowers may be more interested in the larger interest deductions that the monthly-payment mortgage offers. So, the relationship between income and the choice between the BPM and the MPM is not clear. The two effects could, possibly, offset each other.

Some authors refer to the BPM as the "Yuppie Mortgage," the mortgage for young, urban professionals with high income. See DeBat (1986). However, a priori, it is not clear what the effect of education on the choice between the BPM and the MPM would be. To the extent that borrowers with higher education levels tend to 
have higher incomes and net worth than borrowers with lower education levels, borrowers with higher formal education would tend to choose the BPM. They would be in a better position to pay the larger annual payments associated with the BPM. On the other hand, because of the greater tax benefits of larger interest deductions, the MPM may be more appealing to the more educated borrowers.

Furthermore, the more educated borrowers may know more about alternative mortgages and investment products and they may not be impressed by the BPM as the borrowers with lower education might be. For example, a home owner can obtain a MPM and then design a prepayment plan that is equivalent to the BPM without refinancing. The MPM gives the home owner greater flexibility than does the BPM.

As far as age is concerned, we would expect older borrowers to choose the BPM so they can pay off their mortgage sooner and own their homes free and clear before retirement. In addition, older borrowers may have higher incomes and larger net worth and they may be in a better position to handle the BPM. Here, again the greater tax benefit associated with the MPM may lead them to choose the MPM.

Finally, married couples may tend to choose the BPM since they are more likely to have higher incomes than singles. They also benefit from the economies of joint living. On the other hand, the MPM may be more attractive to them than the BPM for tax reasons. With the exception of the frequency of paydays, the effects of the factors discussed above on the choice between the BPM and the MPM is not clear. Some of the factors may lead to the choice of the BPM and others may lead to the choice of the MPM. It is also possible that because of the types of offsetting effects that were discussed above, some of the variables may not have any significant effect on the choice between the two mortgage instruments.

With the exception of age, all the independent variables in this study were treated as categorical variables. Two of the independent variables, income and net worth, had three classes each and they were each represented by two indicator variables. The income classes were under $\$ 35,000, \$ 35,000-70,000$ and over $\$ 70,000$. The net worth classes were under $\$ 100,000, \$ 100,000-300,000$ and over $\$ 300,000$.

With respect to education, there were three classes. Those who completed college, those who completed high school and those who did not complete high school. Since all the respondents were either high school or college graduates, the third class was dropped.

The data for this study were collected from a limited regional survey of home owners and potential home owners in the northern suburbs of Detroit. First, zip codes were selected randomly from a list of zip codes for the northern suburbs of Detroit. Second, 500 addresses were selected randomly from the lists of addresses within the zip codes selected in the first stage. Third, the home owners or potential home owners were asked to supply demographic data and to indicate their choice between the BPM and MPM.

To make sure that the respondents knew what the BPM was and how it differed 
TABLE 1.

Summary of Survey Results

\begin{tabular}{llr}
\hline PAYDAY FREQUENCY: & Biweekly or weekly: & 65 \\
& Monthly: & 19 \\
INCOME: & less than $\$ 35,000$ per year & 6 \\
& between $\$ 35,000 \& \$ 70,000$ & 31 \\
& over $\$ 70,000$ & 47 \\
EDUCATION: & less than college & 10 \\
& college completed & 74 \\
NET WORTH: & less than $\$ 100,000$ & 11 \\
& between $\$ 100,000 \&$ \& & 22 \\
& $\$ 300,000$ & 51 \\
MARITAL STATUS: & over $\$ 300,000$ & 69 \\
& married & 15 \\
AGE: & single, divorced or widowed & 86 \\
& highest & 24 \\
& lowest & 49 \\
& average & 13 \\
\hline
\end{tabular}

from the MPM, a description of the BPM, the differences between the two types of mortgages and a numerical cxample were sent along with the survey form to the home owners or potential home owners. A copy of the description is attached to the manuscript. Also, in order to increase the response rate, the subjects selected for the survey were offered a free evaluation of alternative mortgage prepayment plans. The evaluation involved the determination of the effects of various prepayment plans on the total interest costs and the terms of specific mortgages.

Of the 84 respondents, $58 \%$ selected the BPM and $42 \%$ selected the MPM. Seventy seven percent were paid biweekly or weekly and only $23 \%$ were paid monthly. Eighty-two percent were married and the ages ranged from 24 to 86, with an average of 49. Most of the respondents were college educated and they were in the high income and high net worth categories. The results of the survey are summarized in Table 1.

\section{Results}

Before running the logistic regression, we constructed $2 \times 2$ tables to see if there is any discernible association between the dependent variable and each of the independent variables, except age. The two-by-two tables are shown in Table 2. The odds ratios were computed for each of the $2 \times 2$ tables. 
TABLE 2.

Two by Two Tables

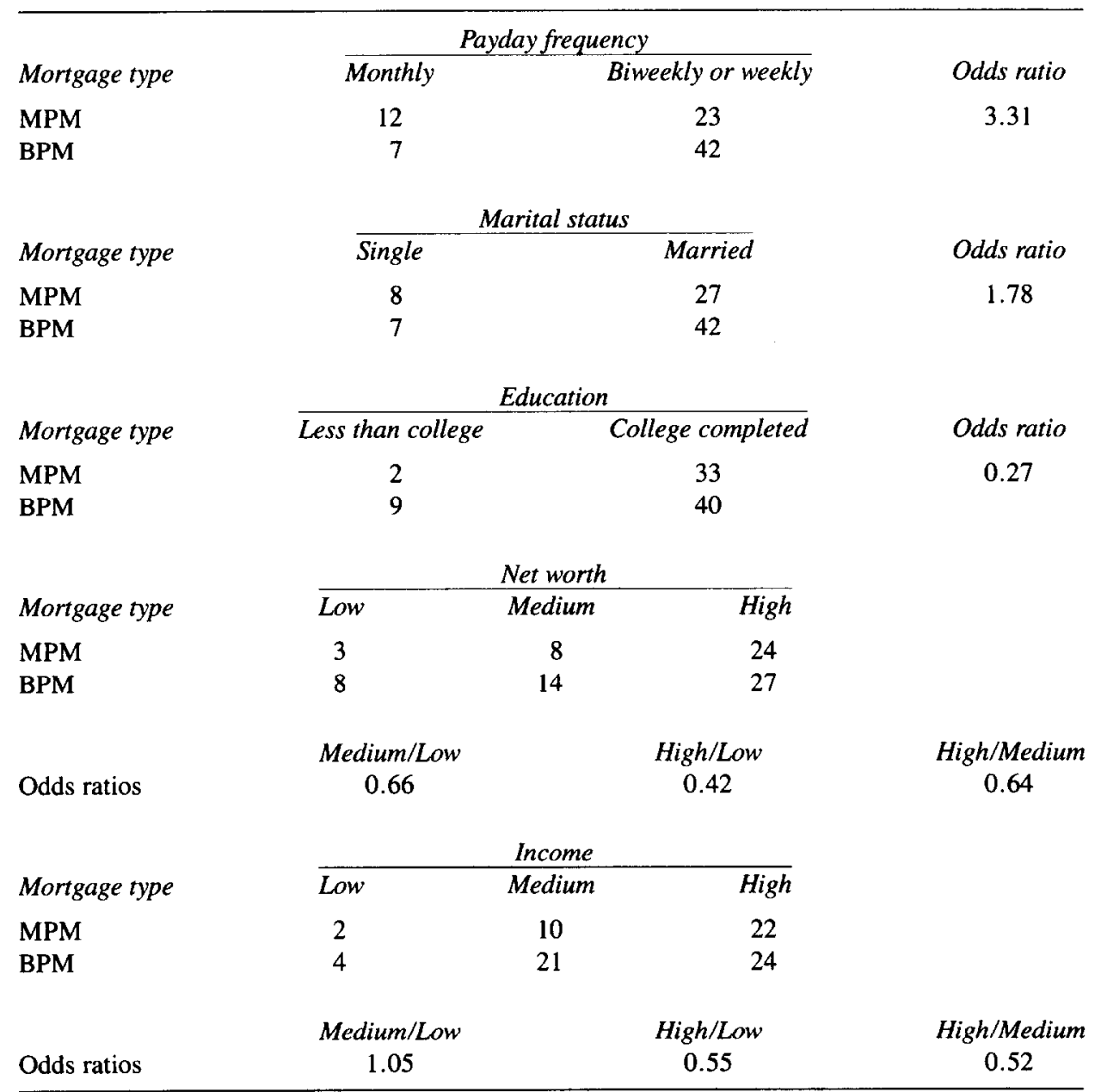

Notes: MPM $=$ Monthly-payment mortgage

$\mathrm{BPM}=$ Biweekly-payment mortgage

Based on the $2 \times 2$ tables and the odds ratios, only two of the independent variables seemed to be strongly associated with mortgage choice. The first one was the frequency of paydays. The odds ratio was 3.31. Home owners that were paid biweekly or weekly tended to prefer the biweekly payment mortgage.

The second important independent variable was education. The odds ratio was 0.27 . The group with a higher education had greater relative preference for the MPM. There seems to be some association between mortgage choice and the other variables, too, but the association does not seem to be as strong as it is with the payday frequency and education. 
The Statistical Analysis System (SAS) was used to estimate the full model, with all the independent variables included. The estimated values for the full model are reported in Table 3. For large samples, the maximum likelihood estimators are distributed approximately normal. For this reason, the usual $\mathrm{Z}$ tests apply. At a significance level of $10 \%$, the coefficients of the payday frequency and incomel (a dummy variable for the medium income category) are significantly different from zero. Also the coefficient of the payday frequency has the expected sign. However, none of the coefficients is statistically significant at the $5 \%$ level of significance. Thus, home owners with medium income and those who are paid weekly or biweekly seem to favor the biweekly-payment mortgage.

TABLE 3.

Estimated Values of the Full Logistic Regression Model

\begin{tabular}{|c|c|c|c|c|}
\hline Variable & Coefficient & Std. Error & P-Value & Odds ratio \\
\hline INTERCEPT & -0.3605 & 2.786 & 0.897 & \\
\hline FREQ OF PAY & 1.3610 & 0.721 & 0.059 & 3.900 \\
\hline INCOMEI & 2.5940 & 1.437 & 0.071 & 13.383 \\
\hline INCOME2 & 1.5557 & 1.466 & 0.289 & 4.738 \\
\hline AGE & -0.0170 & 0.027 & 0.536 & 0.983 \\
\hline EDUCATION & -1.1828 & 1.136 & 0.298 & 0.306 \\
\hline NETWORTHI & -0.6691 & 1.157 & 0.563 & 0.512 \\
\hline NETWORTH2 & -0.8090 & 1.243 & 0.515 & 0.445 \\
\hline MAR STATUS & 1.6980 & 0.880 & 0.054 & 5.463 \\
\hline \multicolumn{5}{|c|}{$\begin{array}{l}\text { Model Chi-square }=14.85 \text { with } 8 \text { degree of freedom } \\
\text { Model } P \text {-value }=0.0621\end{array}$} \\
\hline \multicolumn{5}{|c|}{$\begin{aligned} \text { PAYFREQ } & =1, \text { if paid weekly or biweekly } \\
& =0, \text { if paid monthly }\end{aligned}$} \\
\hline & & & INCOME2 & \\
\hline LOW INCOME & & & 0 & \\
\hline MEDIUM INCOME & & & 0 & \\
\hline HIGH INCOME & & & 1 & \\
\hline \multicolumn{5}{|c|}{$\begin{aligned} \text { EDUCATION } & =0, \text { if less than college } \\
& =1, \text { if college completed }\end{aligned}$} \\
\hline & & rH1 & NETWORTH2 & \\
\hline LOW NETWORTH & & & 0 & \\
\hline MEDIUM NETWORTH & & & $\mathbf{0}$ & \\
\hline HIGH NETWORTH & & & 1 & \\
\hline \multicolumn{5}{|c|}{$\begin{aligned} \text { MARITAL STATUS } & =0, \text { if single, divorced or widowed } \\
& =1, \text { if married }\end{aligned}$} \\
\hline
\end{tabular}


Since we did not find the results of the full model satisfactory, the stepwise logistic regression procedure in SAS was used to generate the final model for this study. The statistics for the final model are given in Table 4 . Here again, the $\mathrm{Z}$ tests indicate that the coefficients of the payday frequency and education are significantly different from zero at both the $5 \%$ and the $10 \%$ levels of significance. In addition, these results seem to be consistent with the observations derived from the individual $2 \times 2$ tables. Only two of the six independent variables, frequency of paydays and education, remained in the final model. Also, note that the model Chi-square is smaller for the final model than for the full model. Furthermore, the odds ratios from the logistic regression indicate stronger relationships between the independent variables and the dependent variable than was suggested by the odds ratios from the $2 \times 2$ tables.

Finally, using a cutoff point of $58 \%$, the estimated logistic regression model correctly classified $68 \%$ of the respondents. A cutoff point of $58 \%$ was used because that was the percentage of the survey respondents who selected the BPM.

\section{Conclusion}

This study examined the effects of various demographic factors on the choice between the BPM and the MPM. Of the six factors that were considered, only two had statistically significant influence on mortgage choice. These factors were the frequency of paydays and education. The importance of the first factor is rather obvious. Ceteris paribus, home owners who are paid weekly or biweekly, are more likely to choose the BPM than home owners who are paid monthly.

The effect of education was, however, surprising. Home owners with college

TABLE 4.

Estimated Values of the Final Logistic Regression Model and Odds Ratios

\begin{tabular}{lcccc}
\hline Variable & Coefficient & Std. error & $P$-value & Odds ratio \\
\hline INTERCEPT & 0.8389 & 0.837 & 0.316 & - \\
FREQ OF PAY & 1.5784 & 0.629 & 0.012 & 4.847 \\
EDUCATION & -1.9342 & 0.917 & 0.035 & 0.145 \\
\hline
\end{tabular}

Model Chi-square $=10.37$ with 2 degree of freedom $P$-valuc $\quad=0.0056$

FREQ OF PAY $=1$, if paid weekly or biweekly

$=0$, if paid monthly

EDUCATION $=0$, if less than college

$=1$, if college completed 
degrees tended to prefer the MPM and home owners with just high school diplomas tended to prefer the BPM. As indicated above, one possible explanation for this result is that the more educated group knows more about alternative mortgage and investment products and that they are not as impressed by the BPM as those with just high school education. For example, a home owner can obtain a MPM and then design a prepayment plan that is equivalent to the BPM without refinancing. The MPM gives the home owner greater flexibility than does the BPM.

Another possible explanation is that the more educated group had higher income and consequently preferred the MPM for the greater tax benefits that it offers. In other words, for the larger interest payments that may be deducted for tax purposes.

The results of this study have implications both for borrowers and lenders. Assuming other factors are held constant, the biweekly-payment mortgage is, obviously, more suited for home owners who are paid weekly or biweekly rather than for those who are paid monthly. From the lender's point of view, the marketing of the biweekly-payment mortgage should focus on home owners who are paid biweekly or weekly. Home owners who are paid monthly or those with college degrees seem to be relatively more interested in the monthly-payment mortgage.

While this study has identified borrower characteristics that are important for the choice between the biweekly-payment mortgage and the monthly-payment mortgage, it must be pointed out that it was based on a limited regional survey. Future studies may be based on national surveys. They may also include other variables that were not considered in this study.

\section{Appendix}

Dear home-owner or potential home-owner:

I am preparing a study of the factors that influence the choice between monthlypayment mortgages and biweekly-payment mortgages. This study will be based on data gathered from a mail survey of home-owners or potential home-owners in this area. I would appreciate it very much if you could take a moment to read this memo and complete the enclosed short form.

In the last few years, some lending institutions in Michigan started offering biweekly mortgages. In a biweekly mortgage, half of the monthly payment of a monthly-payment mortgage is paid every two weeks. Over a period of a year, 26 biweekly payments are made and these payments are equal to 13 monthly payments of a regular monthly-payment mortgage. The extra payment associated with the biweekly mortgage reduces the term of a 30-year mortgage by about one-third.

As an example, suppose you borrow $\$ 75,000$ at $9.75 \%$ interest for 30 years. Your monthly payment would be $\$ 644.37$. If you make biweekly payments of $\$ 322.18$ 
(that is half of $\$ 644.37$ ), the term of the 30-year mortgage would be reduced to about 21 years.

The monthly-payment mortgage involves smaller annual payments and offers larger annual interest deductions for tax purposes. On the other hand, the biweeklypayment mortgage accelerates the pay-off of the mortgage and results in greater equity for the home buyer overtime.

Given this background information about the monthly-payment mortgage and the biweekly-payment mortgage, we would appreciate it if you could tell us which of these two types of mortgages you would choose by completing the enclosed form and returning it to us in the stamped, self-addressed envelope by February 15, 1990. As you can see, the form is completed anonymously.

\section{Form 1. Biweekly vs. Monthly-Payment Mortgages}

Please check the appropriate items below.

YOUR PREFERENCE $\quad \square$ monthly-payment mortgage

$\square$ biweekly-payment mortgage

YOUR PAY CHECKS

RECEIVED

biweekly $\square$ monthly $\square$ other

YOUR ANNUAL

GROSS INCOME

under $\$ 35,000 \square \$ 35,000-70,000$

$\square$ over $\$ 70,000$

AGE IN YEARS

EDUCATION COMPLETED $\square$ less than high school

high school $\square$ college

NET WORTH*

$\square$ under $\$ 100,000 \square \$ 100,000-300,000$

$\square$ over $\$ 300,000$

MARITAL STATUS

married $\square$ single, divorced, widowed

*Net Worth is the amount you would be left with if you sold all your assets and paid off all your debts.

PLEASE RETURN THE COMPLETED FORM IN THE ENCLOSED, SELFADDRESSED, STAMPED ENVELOPE. 


\section{Form 2. Prepayment Options}

If you already have a mortgage, you may be able to reduce the term of your mortgage without refinancing if your lender allows partial prepayments without penalty. There are various prepayment options. You could make additional principal payments monthly, quarterly, semi-annually or annually. You could also make lump-sum payments.

For a FREE evaluation of various prepayment options, fill the blanks below and we would be glad to prepare a customized evaluation. You may get some of the information requested from your mortgage documents or your bank.

\section{ITEM}

AMOUNT

Current loan balance

Remaining term of the loan in years

Annual interest rate (note rate) in \%

Current principal \& interest payment

Amount of additional principal payments you wish to make (you may fill one or more blanks)

\section{PREPAYMENT PLAN}

One-time, lump-sum

Monthly

Quarterly

Semi-Annual

Annual

\section{AMOUNT}

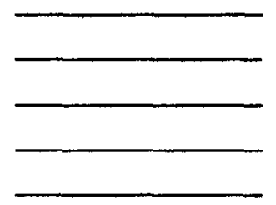

NOTE: FOR PURPOSES OF ANONYMITY, PLEASE RETURN THIS FORM IN A SEPARATE ENVELOPE.

Acknowledgments: The author wishes to thank the Campus Grants Committec of the University of Michigan-Dearborn for financial support.

\section{REFERENCES}

Brueckner, Jan K., and James R. Follain. 1988. "The Rise and Fall of the ARM: An Econometric Analysis of Mortgage Choice," Review of Economics and Statistics, February: 93-102.

Chmura, Christine. 1989. "Choosing Between an Adjustable Rate and a Fixed Rate Mortgage," pp. 68 in Federal Reserve Bank of Dallas, Cross Section, Summer. 
DeBat, Don. 1986. The Mortgage Manual. Chicago: Contemporary Press.

Dhillon, Upinder, James Shilling, and C.F. Sirmans. 1987. "Choosing Between Fixed and Adjustable Rate Mortgages," Journal of Money, Credit and Banking, February: 260-267.

Dhillon, Upinder, James Shilling, and C.F. Sirmans. 1990. "The Mortgage Maturity Decision: The Choice Between 15-Year and 30-Year FRMs," Southern Economic Journal, April: 1103-1116.

Gardner, Mona J., Han Bin Kang, and Dixie L. Mills. 1987. "Consumer Profiles and Acceptance of ARM Features: An Application of Logit Regression," Journal of Real Estate Research, Winter: 63-74.

Rossi, Peter, J. Wright, and A. Anderson. 1983. Handbook of Survey Research. New York: Academic Press.

Shilling, J.D., and C.F. Sirmans. 1987. "Pricing Fast-Pay Mortgages: Some Simulation Results," Journal of Financial Research, Spring: 25-32.

Tucker, Michael. 1989. "Adjustable Rate and Fixed Rate Mortgage Choice: A Logit Analysis," Journal of Real Estate Research, Spring: 81-90.

Yohannes, A.G. 1986. "Comparing Mortgages with Different Terms," Real Estate Review, Fall: 9396.

Yohannes, A.G. 1988. "Evaluating Alternative Fast-Pay Mortgages," Journal of Real Estate Research, Fall: 23-29. 